\title{
Utilisation study of mobile technology at a vocational high school
}

\author{
Ridwan D. Mahande $†$ \& Jasruddin $¥$ \\ Universitas Pepabri Makassar, Makassar, South Sulawesi, Indonesia† \\ Universitas Negeri Makassar, Makassar, South Sulawesi, Indonesiał
}

\begin{abstract}
This article aims to describe content aspects, user aspects and social aspects of the use of mobile technology in vocational schools in Makassar, South Sulawesi, Indonesia. This research was quantitative descriptive in nature. The populations in this study were teachers and students at a vocational high school in Makassar. The research samples were 54 teachers and 150 students, selected by using the purposive sampling technique. The data were collected using questionnaires and interviews. Data were then analysed using descriptive analysis techniques. The results showed that the content aspects were based on learning objectives, and content-based images, media and text are in the very high category. User aspects indicate that the use of mobile technology to access interactive information related to the learning and vocational training are in the very high category. Social aspects show that ethics and interaction through mobile technology to facilitate the need for information skills are also in the very high category.
\end{abstract}

\section{INTRODUCTION}

In regard to, the development and ownership of mobile technology, the results of research conducted by the Association of Indonesian Internet Service Provider in 2000 showed that 85\% of Internet users in 42 cities in Indonesia are more often connected through mobile phones. It is due to the availability of an increasing number of affordable smartphones in the market. In addition, the cost of access is also increasingly economical [1]. In relation to this issue, users of the Internet via mobile phones or smartphones, make up $85 \%$, followed by $32 \%$ via laptop, $14 \%$ via PC and $13 \%$ via tablets [1]. The advent of new technologies, such as mobile technology has the potential to create a learning environment that is more flexible. It also can increase the role of mobile technology as a platform for e-learning or electronic learning [2].

The emerging use of mobile technology has an impact on learning at vocational high schools. Sharples states that mobile technology completes the learning in classroom formally with informal learning situations outside the classroom [3]. Furthermore, with mobile technology, it is possible to transfer knowledge through collaborative interactions between workers in the world of work to students in schools, and vice versa, from school to the working world [4]. Students can access information and resources that are relevant to education and vocational training, which are up-to-date on the Web, as well as to communicate with teachers and instructors in the working world in a field of expertise. This statement implies that the use of mobile technology at vocational high schools will support collaborative interaction and competence, which is of relevance to the world of work.

As mentioned above, the high technology mobile users can access the Internet, but advantages gained from the application of mobile technology in learning are often not synchronised, between the theory and complex implementations in the field. It has been visible by the lack of use of mobile technology in learning. As information seekers, the Internet users in Makassar reached 3.7 million people (44\%). About $78 \%$ of the devices used to access the Internet are smartphones [1]. The data indicate that Internet access via smartphones in Makassar is in the very high usage category, but it has not yet been used for learning.

The results of the initial survey conducted by the researchers at vocational high schools in Makassar showed that most of the people in those vocational schools had had a mobile technology, such as mobile phones, smartphones and tablets. However, the devices were more widely used for communication to send and receive messages, to access multimedia information, and to access social media, which is not in accordance with vocational learning.

Another problem of the lack of use of mobile technology in learning is the lack of awareness of the school community, especially teachers, about the importance of this technology to be utilised as part of ICT-based learning. In fact, if mobile technology were used optimally in vocational learning, it would facilitate teachers and students in acquiring, 
transferring and receiving information, knowledge and skills, wherever and whenever. However, although the potential of mobile technology to transform learning significantly seems obvious, the teachers are apparently not so convinced.

Based on the results of a survey in the field, the lack of use of mobile technology for learning is due to the low level of ability of teachers and a slow pace of change in educational institutions. In addition, instructional design is not always suitable for education [5]. Furthermore, the challenge of using mobile technology in learning includes social and physical factors, such as the potential disruption or negative behaviours, physical health problems and issues of privacy of data [6]. Additionally, mobile technology could also be expected to affect the usefulness and can distract children from learning objectives. These challenges also seem to provide relevant information to determine the readiness of users, the content of mobile technology, which is appropriate for learning, and learning social interaction that should be conducted through a mobile device.

Those problems confirm the need for an in-depth study on the utilisation of mobile technology in learning at vocational high schools. Issues are: the readiness of the learning content, user readiness and social interaction in learning. These issues can be grouped into three main aspects in line with the theory of frame models; namely, the content aspects, user aspects and social aspects [7].

The contents aspects are part of the device aspects of the frame models, which describe learning content or any content commonly accessed by teachers and students through mobile technology owned. The content of mobile technology for learning is crucial for matching the learning objectives at vocational high schools. Good judgement is critical for understanding the purpose and the specific function of the type of content that is generated [8]. All content can be engaging and useful if individuals need it and use it for their purposes. Similarly, in mobile technology for learning, teachers and students can be attracted by content that is created and displayed, as well as to obtain information for the development of knowledge.

User aspects describe how students utilise mobile technology for learning purposes at vocational high schools. It is focused on students' cognitive abilities and prior knowledge, characteristics and habits of learners with mobile technology [9]. Furthermore, in the user aspects, it is important to consider memory, knowledge transfer, learning by discovery and motivation [7]. These aspects explain how students use what they already know, to access, identify, store and transfer information.

The social aspects illustrate the ethics and behaviour of students in the use of mobile technology in learning. In addition, the social aspects demonstrate how students communicate, collaborate and interact through mobile technology they own. These aspects refer to social interaction [7] and collaboration, information access and contextual learning [9][10]. According to Vygotsky, social interaction and collaboration are essential for the learning of socio-cultural perspective as individuals who engage in meaningful discussions [10]. Because of the importance of interaction and collaboration in these aspects, students, teachers and instructors are required to follow the rules of collaboration in communicating, exchanging information, acquiring or constructing knowledge, and maintaining the cultural practices of learning. The rules of this collaboration are determined by the culture of learners in which the interaction occurs both physical and virtual.

Mobile technology has the potential to expand where, how and when an individual or group learn in all aspects of life. One of the major benefits of mobile technology in learning is its potential to increase productivity by making learning available anywhere and anytime [11]. Mobile technology can be the first step towards just-in-time learning. The advantages offered by mobile technology must be effectively conceptualised to suit electronic learning or e-learning. The default application, social networking applications, as well as learning content must be integrated. They also must contain learning information which is useful for teachers and students in the world of vocational education.

There is certainly enormous potential for mobile technology to be utilised in education, but in reality, it is not the case. Several researchers have conducted investigations in order to optimise the potential of mobile technology in education. One example is research on the impact of mobile technology features on traditional teaching in regard to the pedagogical side through the utilisation [12].

Mobile technology is present not to complicate the learning, but to facilitate the creation or acquisition of more innovative learning. Furthermore, the research on meta-synthesis was introduced to design the mobile platform for entrepreneur engineering education and classroom teaching modes. This research confirms that the flipped classroom based on m-learning has a positive role in improving students' learning motivation and cooperation ability, learning efficiency and satisfaction in class [13]. Another research has been carried out on the effectiveness of the use of mobile technology to support learning in schools [14]. This research confirms that most students were satisfied with the use of mobile technology for learning in the classroom.

These studies are still limited to a general area of the utilisation of mobile technology features and the influence of mobile technology on learning in school. The results of previous research have not specifically focused on the aspects of the use of mobile technology in learning, especially at vocational high schools. Therefore, further research on the use of mobile technology for learning is needed. 
Thus, it is important to conduct a study on the utilisation of mobile technology for learning at vocational high schools in Makassar. This study aims to describe content aspects, user aspects and social aspects of the use of mobile technology in such schools in Makassar. This study is a form of sustainable development in education, which is not only created, but also developed continuously, because science and information acquired by teachers and students must always be up-to-date.

\section{METHOD}

This research is a quantitative descriptive study, with an attempt to reflect events that have occurred in the present in the form of significant figures. The population of the study is teachers and students at Vocational High School 1, Vocational High School 2 and National Vocation School, all in Makassar. The research samples were 54 teachers and 150 students, selected by using the purposive sampling technique with certain considerations as per the purpose of this research. The data were collected using questionnaires and interviews. The data were, then, analysed using descriptive analysis to find out the characteristics of each variable and to perform a physical representation of research problems based on the score achieved by the respondents.

\section{RESULTS}

Figure 1 shows that in the content aspects, 40 teachers (74.1\%) are in the very high category and 14 teachers (25.9\%) are in the high category. These data indicate that the teachers' perception on the use of mobile technology to access learning content at vocational high schools is in the high to the very high category.

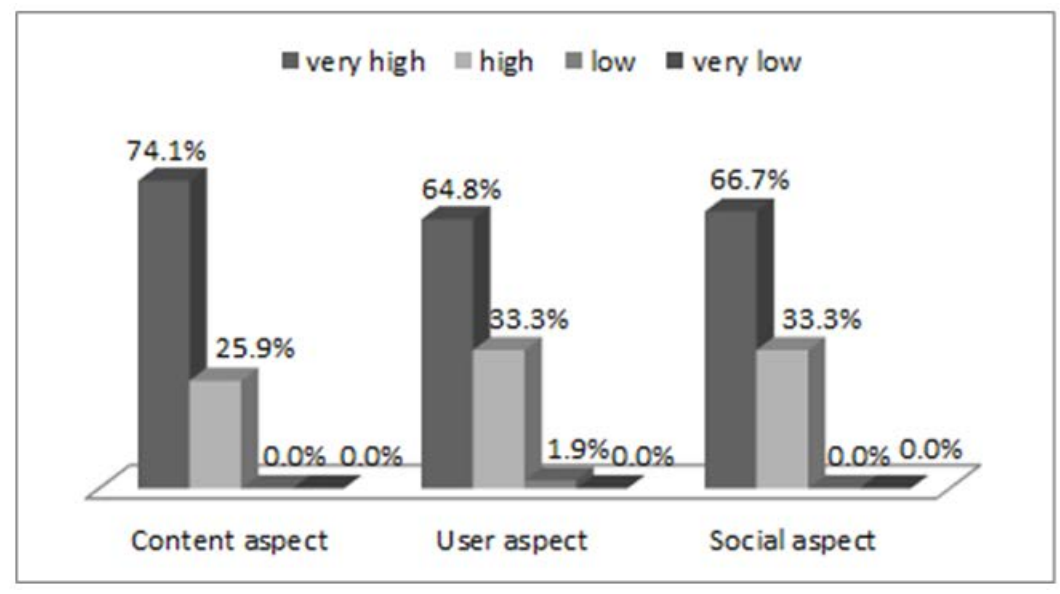

Figure 1: Utilisation of mobile technology by teachers.

In the user aspects, 35 teachers (64.8\%) are in the very high category, 18 teachers (33.3\%) are in the high category, and one teacher $(1.9 \%)$ is in a low category. These data indicate that teachers' perception on the use of mobile technology for learning at vocational high schools is in the high to the very high category. However, there is still a percentage that is included in the low category, which requires further attention.

In the social aspects, 36 teachers (66.7\%) are in the very high category, 18 teachers (33.3\%) are in the high category. These data indicate that the teachers' perception of the social aspects of the use of mobile technology is included in the high to the very high category.

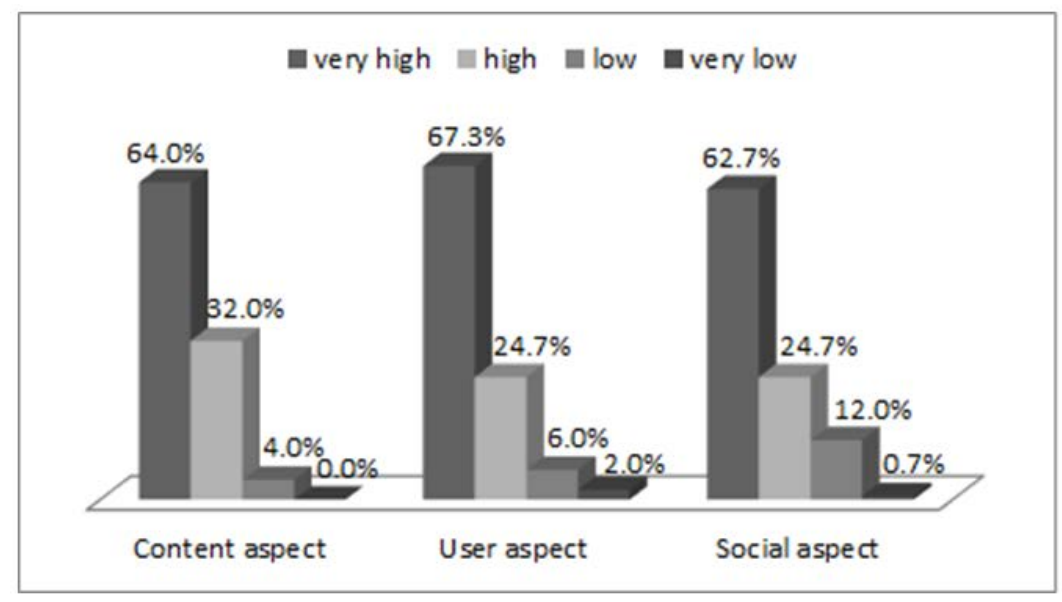

Figure 2: Utilisation of mobile technology by students. 
Figure 2 shows that in the content aspects, 96 students (64\%) are in the very high category, 48 students (32\%) are in the high category and six students (4\%) are in a low category. These data indicate that the students' perception regarding the use of mobile technology to access learning content at vocational high schools is included in the high to the very high category. Therefore, further attention toward those students that are in the low category is required.

Regarding the user aspects, 101 students (67.3\%) are in the very high category, 37 students (24.7\%) are in the high category, nine students (6\%) are in a low category, and three students (2\%) are included in the very low category. These data indicate that the students' perception regarding the use of mobile technology for learning at vocational high schools is included in the very low to the very high category. Therefore, further attention toward those students in the low and extremely low category is required.

In terms of the social aspects, 94 students (62.7\%) are in the very high category, 37 students (24.7\%) are in the high category, 18 students (12\%) are categorised as the low category, and one student $(0.7 \%)$ is included in the very low category. These data indicate that the students' perception of the social aspects of the use of mobile technology is included in the low to the very high category. Therefore, as with the content aspects and the user aspects, the social aspects also require further attention toward those students in the low and extremely low category.

Based on the frequency distribution, the aspects of the use of mobile technology according to the teachers' perceptions and students' perception, the achievement score of the three aspects at vocational high schools can be known by comparing the total score achieved for each set of aspects empirically with the highest total score for each set of aspects assigned theoretically. Descriptive analysis of the three aspects for both teacher and student perceptions, is visually presented in Figure 3.

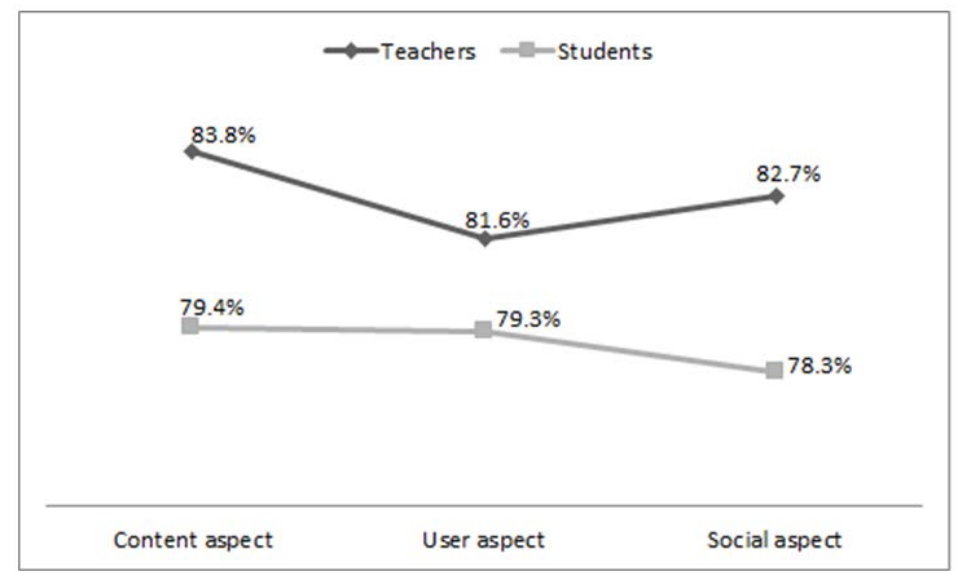

Figure 3: Aspects of the utilisation of mobile technology in vocational schools.

Figure 3 shows the results of the descriptive analysis of the three aspects. According to the teachers' perception, the content aspects are $83.8 \%$, the user aspects are $81.6 \%$ and the social aspects are $82.7 \%$. Meanwhile, according to the students' perceptions, the content aspects are $79.4 \%$, the user aspects are $79.3 \%$ and the social aspects are $78.3 \%$.

\section{DISCUSSION}

\section{Utilisation of Mobile Technology by Teachers Based on Content Aspects}

Descriptive analysis showed that $83.8 \%$ of teachers utilise mobile technology to access vocational learning content available on various Internet sites. This fact shows that learning content, which is most frequently accessed by teachers through mobile technology is the content according to the learning objectives at vocational high schools. Learning content in the form of a picture (photo, map and chart), media (video tutorial/podcasts) and text (Word, PDF, PPT) are the content that is felt to be crucial and frequently accessed by teachers. The three types of content aim to support learning and vocational training. In addition, teachers often use cameras and video from a mobile device to obtain content from various locations related to learning and vocational training. It means that the facilities of mobile technology can be used to obtain the learning content. In addition, there are also communications facilities via e-mail and discussion forums. In this regard, the learning content, which is provided and can be accessed through mobile technology needs to be sorted properly.

Although the analysis shows high and even very high utilisation, there still is a finding that aspects of the content are under the average value. Teachers do not frequently utilise mobile technology to access learning content on YouTube or other sites. It is similar to the lack of access to learning content that provides interactive multimedia facilities. In addition, when the content was accessible, communication facilities that could be used in a synchronised manner, such as video conferencing facilities have not yet been fully provided. Also, navigational tools that could help teachers to preserve the learning content have not yet been provided. 
Descriptive analysis showed that $81.6 \%$ of teachers had taken advantage of mobile technology for learning purposes at vocational high schools. This fact confirms that teachers very often use mobile technology to access information related to the learning and vocational training. The intended information is an interactive learning information. It is crucial that mobile technology helps teachers to find information that is relevant to the needs of learning and, especially, mobile technology can be used to take pictures and video learning.

However, teachers still do not fully believe that the use of mobile technology will be able to reduce the cognitive load (load memory). It could happen, if the facility or feature in mobile technology has not been used as an external memory, which will be able to reduce the cognitive load. In addition, teachers infrequently access the content of employment sites. Moreover, teachers are also informed that it is very important for them to access interactive multimedia-based content, but in reality, mobile technology has not been fully utilised by the teachers for video tutorials or simulation in learning theory and practice. In a different situation, it turns out that the use of mobile technology by teachers has been concentrated on one point only, and not anywhere and anytime. Teachers also do not fully believe that the use of mobile technology can provide comfort in learning. It implies that the use of mobile technology is not only for the convenience of learning, but also other things, which are more important than that.

\section{Utilisation of Mobile Technology by Teachers Based on Social Aspects}

Descriptive analysis showed that $82.7 \%$ of teachers had taken advantage of mobile technology to communicate, collaborate, interact and build a learning community that is in accordance with vocational learning. This fact confirms that in terms of the social aspects, if the provision of space for the media or forum-based community development work, such as a dual system of education and internships are crucial to being prepared. It is followed by the importance of ethics in the use of mobile technology for learning. More specifically, some teachers stated that mobile technology is used for interaction between learning and the instructor in work practices. That interaction facilitates the need for information skills development. In addition, teachers also take advantage of mobile technology to communicate with friends on vocational learning.

Although the analysis shows high or even very high utilisation, there is still a finding that the social aspects are under the average rate. Although teachers interact, to some extent, to communicate and collaborate with instructors in the workplace as an effort to gain a relevant competence at vocational high schools, full utilisation is still lacking, and it is similar to the communication with friends. Although teachers often communicate, to collaborate with friends on vocational learning is still lacking.

\section{Utilisation of Mobile Technology by Students based on Content Aspects}

Descriptive analysis showed that $79.4 \%$ of students take advantage of mobile technology to access vocational learning content, which is available on various Internet sites. This fact confirms that it is important for students to access and to download content-based learning media (video tutorials, podcasts), images (photos, maps, graphs) and text-based (PDF, Word, PPT) for the purpose of learning and vocational training. In general, the students expressed that they often access content. which is appropriate to learning objectives and the importance of learning content are sorted properly. Furthermore, the students expressed that they often access learning content that provides interactive multimedia facilities in accordance with vocational learning. It is in connection with previous statements regarding content-based media.

However, sites providing navigation that can help students not to lose their learning content are still infrequent. It is the same case with the use of video cameras and mobile technology to obtain learning content from various locations, which is also still very sparingly utilised. In addition, students have a low perception of learning content that provides communication facilities that can be used at different times, such as email and forums, especially, in asynchronous communication facility, such as video conferencing. It is followed by the low utilisation of mobile technology to access learning content on YouTube.

\section{Utilisation of Mobile Technology by Students based on User Aspects}

Descriptive analysis showed that $79.3 \%$ of students take advantage of mobile technology for the purpose of vocational learning. This fact confirms the very high utilisation of mobile technology to access information related to vocational learning and training. The intended information is learning information, which is more interactive. In addition, the use of mobile technology is more geared to find information relevant to the needs of vocational learning. Accessing information via mobile technology is made by students anywhere, anytime. This is unlike the case with teachers who are concentrated in one place.

However, students are still lacking in using the mobile technology to access content from the sites of employment. It is similar to the teachers, and the students do not also still fully believe that the use of mobile technology will be able to reduce the cognitive load. In addition, the students also expressed that it is not so important for them that people in their 
environment, such as principal, teachers, friends and family encourage them to take advantage of mobile technology for learning. As with teachers, the students also pointed out that the use of mobile technology is not only to provide the convenience of learning, but also more that. Furthermore, the students provided information that they used mobile technology to take pictures and video learning, especially for learning simulations that are not fully utilised at school.

\section{Utilisation of Mobile Technology by Students based on Social Aspects}

Descriptive analysis showed that $78.3 \%$ of students take advantage of mobile technology to communicate, collaborate, interact and build a learning community that is in accordance with vocational learning. This fact shows the need for providing a forum for the development of community-based work, such as internships. It is followed by the importance of promoting ethics in the use of mobile technology for learning. More specifically, with the social aspects of utilisation, the students expressed that they often interact with mobile technology to facilitate the need for information skills development.

Nevertheless, mobile technology to interact, communicate, collaborate with instructors in the workplace as an effort to have a relevant competence obtained at vocational high schools is not used maximally. It is followed by the low utilisation of mobile technology to communicate and interact with teachers. More importantly, it shows that mobile technology to interact with the learning content in vocational high schools is not used maximally. Although in the beginning, in relation to the aspects of the content, it has been explained that interaction of content in the social aspects is associated with a lower rate of the utilisation of content through mobile technology.

\section{Utilisation of Mobile Technology in Vocational Schools in Makassar}

In Figure 3, a comparison is presented between the use of mobile technology as perceived by the teachers and students. The highest aspects of the use of mobile technology according to teachers' perceptions are the content aspects, then, social aspects and user aspects. Meanwhile, according to the students' perceptions, aspects of the content are the highest, and they are followed by the user aspects and social aspects. Both perceptions provide indicate that the use of mobile technology to access learning content has the highest rate. It means that mobile technology has been more widely used to access learning content.

Further, the results show that the learning content, which is most frequently accessed by teachers and students through mobile technology is the learning content, which is appropriate for learning objectives; namely, image-based content, media and text. The utilisation of mobile technology, which is effective for learning is the utilisation that allows students to interact using mobile applications, such as text messages, multimedia, audio or video [7].

However, the use of mobile technology to access learning content on YouTube is still very low. Although YouTube provides content-based media, YouTube has not been fully used for the purpose of such content, but there are still many video applications can be used. In addition, the site has not fully provided communication facilities that may be used in a synchronised manner, such as video conferencing. Besides, it has not yet provided navigation that can help teachers and students not to lose their learning content.

Furthermore, in terms of the user aspects, teachers tend to be less frequent users than students. It means that students more widely use mobile technology for learning purposes at vocational high schools than teachers. In terms of the user aspects, the teachers and students stated that they often access information related to vocational learning and training or practice. Effective mobile technology will allow students and teachers to gather and select the information, which is relevant to the context and required information [7]. The intended information is learning information, which is more interactive. However, the use of mobile technology by the teacher to obtain information, is a simple use and is concentrated in one place or time, while the students take advantage of mobile technology whenever and wherever. It is one of the things that can cause mobile technology to be mostly used by students rather than teachers.

Nonetheless, both the teachers and students stated that the low utilisation of mobile technology lies in the lack of utilising mobile technology to access content from the sites of employment. In addition, the teachers and students do not fully believe that the use of mobile technology will be able to reduce the cognitive load. Similarly, the teachers and students said that the use of mobile technology is not only to provide the convenience of learning, but also more than that. Further, a distinguishing user aspect between teachers and students is the support from surrounding environment. The teachers stated that the people in the environment, such as leaders, other teachers, friends and family encourage the use of mobile technology for learning purposes. Meanwhile, the students expressed the view that support from the surrounding environment is not so important in encouraging them to use mobile technology. Two differing perceptions related to the support from the surrounding environment require further investigation.

In the social aspects of utilisation, teachers tended to have higher than the students. However, both teachers and students stated that the provision of space for the media or forum-based community development work, such as internship is important. It is followed by the importance of ethics in the use of mobile technology for learning. More specifically, the teachers and students expressed the opinion that they often interacted through mobile technology to facilitate the need for information skills development. An aspect that has a low rate is that although the teachers make some effort to 
communicate and collaborate with instructors in the workplace (as an effort to gain relevant competence at vocational high schools), it could be performed better by the teachers. This was similarly expressed by the students. The difference is that the teachers are still used to having interactions with instructors in the workplace, but the students do not fully interact, communicate and collaborate with them. Effective criteria have not yet been found, and this requires further attention in the use of mobile technology. The utilisation of mobile technology, which is effective for learning is the use of mobile technology for the improvement of knowledge in which students can interact with teachers and instructors regarding the subject matter of different virtual environments [7].

\section{CONCLUSIONS}

The content aspects provide information that the learning content, which is most frequently accessed by teachers and students through mobile technology is that which is synchronised with learning objectives; namely, content-based image-based and text-based media.

In terms of user aspects, the teachers and students expressed the view that they often access interactive information related to vocational learning and training.

In terms of social aspects, the teachers and students stated that the provision of space for the media or forum-based community development work, such as the dual system of education, internship and apprentices is very important. This is followed by the importance of ethics in the use and interaction through mobile technology to facilitate the need for information skills development.

\section{ACKNOWLEDGMENT}

The authors would like to take this opportunity to thank to all parties, especially the Chairman of Research Institute of Universitas Negeri Makassar and staff who have given the trust and support of the research process. Sincere thanks are directed towards teachers, staff and students of Vocational High School 1, Vocational High School 2 and the National Vocational School in Makassar that have provided the opportunity and dedicated their time to assist in the data collection process. Lastly, many thanks to our team and the reviewers of UNM Research Institute for facilitating and guiding the writing of this article.

\section{REFERENCES}

1. Marius, P. and Anggoro, S., Profil Pengguna Internet Indonesia 2014. APJII Jkt. (2015) (in Indonesian).

2. Uhomoibhi, J., Male, G. and Pattinson, C., Enhancing the quality of e-learning through mobile technology: a socio-cultural and technology perspective towards quality e-learning applications. Campus-Wide Infor. Systems, 28, 5, 331-344 (2011).

3. Fazlina, S., Manap, A.A. and Rias, R.M., Mobile learning awareness among students at higher learning institutes: a case study. Proc. 2013 Inter. Conf. on Informatics and Creative Multimedia, IEEE; 226-229 (2013), 13 March 2017, http://ieeexplore.ieee.org/abstract/document/6702814/

4. Ally, M. and Prieto-Blázquez, J., Quin és el futur de l'aprenentatge mòbil en l'educació? RUSC, Universities and Knowledge Society J., 11, 1,142-151 (2014).

5. Peters, K., M-learning: positioning educators for a mobile, connected future. Inter. Review of Research in Open and Distributed Learning, 8, 2 (2007).

6. Pachler, N., Bachmair, B. and Cook, J., Mobile learning: structures, agency, practices. Springer Science \& Business Media (2009).

7. Koole, M.L., A model for framing mobile learning. Mobile Learning: Transforming the Delivery of Educ. and Training, 1, 2, 25-47 (2009).

8. Wuebben, J., Content is Currency: Developing Powerful Content for Web and Mobile. UK: Hachette (2011).

9. Kenny, R.F., Park, C., van Neste-Kenny, J.M., Burton, P.A. and Meiers, J., Using mobile learning to enhance the quality of nursing practice education. Mobile Learning: Transforming the Delivery of Educ. and Training, 1, 75 (2009).

10. Kearney, M., Schuck, S., Burden, K. and Aubusson, P., Viewing mobile learning from a pedagogical perspective. Research in Learning Technol., 20 (2012), 14 March 2017, http://journals.co-action.net/index.php/rlt/article /view/14406

11. Brown, T.H., The role of m-learning in the future of e-learning in Africa. Proc. 21st ICDE World Conf.. 122-137 (2003).

12. Jeng, Y-L., Wu, T-T., Huang, Y-M., Tan, Q. and Yang, S.J.H., The add-on impact of mobile applications in learning strategies: a review study. Educational Technol. \& Society, 13, 3, 3-11 (2010).

13. Liao, Y. and Liu, Z., Meta synthesis design for entrepreneur engineering education using flipped classroom based on m-learning. World Trans. on Engng. and Technol. Educ., 13, 4, 603-608 (2015).

14. Kong, S.C., Using mobile devices for learning in school education. Proc. 2012 IEEE Seventh Inter. Conf. on Wireless, Mobile and Ubiquitous Technol. in Educ., IEEE 172-176 (2012), 14 March 2017, http://ieeexplore.ieee. org/abstract/document/6185020/ 